\section{Implementación de procesos sostenibles vinculando industrias regionales: Reciclaje de residuos siderúrgicos como proyecto de cambio de la manpostería en Boyacá-Colombia}

\author{
Implementation of sustainable \\ processes in regional industries: \\ recycling of metallurgical residuals \\ as a project to change masunry used \\ in construction in Bogota, Colombia.
}

Mise en place de processus de

développement durables grâce à

l'appui d'industries régionales : le

recyclage des résidus sidérurgiques

comme projet de transformation

de la maçunnerie traditionnelle du

département de Bayacá - Colombie

\section{Implementaçãa de processas}

sustentáveis com a participaçãa de

indústrias regionais: reciclagem de

resíduos siderúrgicas como projeto

para a mudança da alvenaria em

Buyacá - Calômbia
FECHA DE RECEPCIÓN: 9 de junio FECHA DE APROBACIÓN: 12 de julio Pp. 82-103

\section{Leonardo Quijano B. * H.Mauricio Díez-Silva** Maricela I. Montes-Guerra*** Hugo Fernando Castro Silva ${ }^{* \star * *}$}




\section{RESUMEN}

En este artículo, se analizan las posibilidades para la implementación de un nuevo proceso viable desde el punto de vista ambiental y económico, que vincule a dos industrias regionales en el marco de la generación de soluciones sostenibles para la economía regional. Se describe la forma de utilizar los residuos de la industria del acero como insumo para la transformación de la industria de mampostería, las dos ubicadas en la región de Boyacá.

\section{ABSTRACT}

This paper shows the analysis of the possibilities to implement a new process, viable from the environmental and economic point of view, which includes two regional industries within the framework of the generation of sustainable solutions for the regional economy. In it, the description of how to use residuals from the steel industry as a source to transform the masonry industry, both located in the region of Bogota.

\section{RESUMÉÉ}

Cet article analyse les potentialités de mise en cuvre d'un nouveau procédé, viable du point de vue environnemental et économique, unifiant les deux industries départementales dans le cadre de la création de processus de développement durables pour l'économie régionale de Boyacá. Nous analyserons la façon d'utiliser les résidus de l'industrie sidérurgique comme entrant pour la transformation de la maçonnerie traditionnelle de la région de Boyacá

\section{RESUMO}

Este artigo analisa as possibilidades para a implementação de um novo processo, viável desde a perspectiva ambiental e econômica, que inclua duas indústrias regionais dentro do plano para a geração de soluções sustentáveis para a economia regional. Descreve-se a maneira de utilizar os resíduos da indústria do aço como insumo para a transformação da indústria alvenaria, ambas localizadas na região de Boyacá.
Palabras clave

Procesos sostenibles

Reciclaje de residuos

Industria de alfarería

Industria del acero

\section{Keywords}

Sustainable processes

Recycling of residuals

Pottery industry

Steel industry.

\section{Mots clefs}

Processus de développement durables Recyclage des déchets

Industrie de la maçonnerie traditionnelle Sidérurgie

\section{Palavras-chave}

Processos sustentáveis

Reciclagem de resíduos

Indústria de cerâmica Indústria do aço. 


\section{INTRODUCCIÓN}

$\mathbf{U}$ na realidad indiscutible para los sectores industriales en todos los ámbitos, regiones y contextos geográficos, se relaciona con la búsqueda por realizar actividades enmarcadas dentro de parámetros de sostenibilidad desde una perspectiva integral. En ese sentido, según Martinera y otros (2002), en una economía mundial como la actual, caracterizada por una fuerte industrialización, el desarrollo sostenible ha generado un interés creciente por la reutilización de residuos generados por las diferentes industrias.

No obstante, desde el siglo pasado los problemas ambientales generados por el impacto de un determinado producto, fueron considerados como problemas locales (Berkhout \& Smith, 1999). Sin embargo, según los autores, actualmente son mucho más evidentes las circunstancias y mucho más complejos los problemas que se relacionan con todas las fases del ciclo de vida de los productos, desde la extracción de la materia prima hasta la disposición y reutilización de los desechos del producto y de los desechos generados en su proceso de producción.

Por ejemplo según Walker (1999), el uso de materiales empleados hoy en día para generar la energía y para fabricar y envasar productos, ha aumentado por lo menos veinte veces por habitante en muchos países industrializados, desde finales del siglo XIX hasta la actualidad. En ese sentido, cada vez se requieren más componentes y se mezclan más materiales para fabricar productos, exigiendo un mayor consumo de energía en todo el mundo, por tanto, la naturaleza no puede mantener la tasa de crecimiento de hasta 5\% que se presenta actualmente en algunos países, sin graves consecuencias a largo plazo (Meadows, 1992).

Conviene considerar que las actividades humanas no han logrado ser capaces de cooperar con la naturaleza con relación a la sostenibilidad, puesto que sólo un pequeño porcentaje del material y energía requerida para los productos que se fabrican hoy en día, se utiliza para el propio producto, lo demás son pérdidas y emisiones de residuos (Ayres, 1997). En últimas, si todas las empresas llegaran en este momento a cero emisiones, la Tierra seguiría por mucho tiempo siendo afectada por ellas (Hart, 1997).

De acuerdo con lo planteado y según las circunstancias actuales, además de los retos de la sostenibilidad para el planeta, se plantea el reto para las industrias de todas las regiones y sectores por la búsqueda permanente de alternativas de producción sostenibles. En consecuencia, dichos retos se deben hacer tangibles en cada proceso de la cadena de valor, buscando, como se ha mencionado, espacios de reutilización de desechos en nuevas alternativas de fabricación.

Cabe señalar que el mercado mundial se ha visto influenciado por políticas ambientales y un interés creciente de la población por salvaguardar el medio ambiente, dando lugar a segmentos de mercado que privilegian los productos verdes y a empresas dedicadas a satisfacerlos mediante la recolección y tratamiento de residuos provenientes de diferentes procesos productivos (Umwelttechnik \& Beratung, 2007). En ese sentido, se evidencia también que desde hace varios años se ha intentado generar un cambio, a través de llamados de atención sobre el tratamiento adecuado de los residuos industriales (Hincapié \& Aguja, 2003).

De las anteriores circunstancias nace el hecho de que emplear los residuos industriales puede ser una alternativa sostenible, dada la desarrollada especialización de diversos sectores de la economía que se dedican a la transformación de materiales (Boada, 2003). En consecuencia, se puede destacar este hecho, observando que el reciclaje de materiales ha venido ganando aceptación como una alternativa para reducir el impacto ambiental negativo de las actividades productivas (Medina, 1999), lo cual, desde una óptica de sostenibilidad, tiene un menor efecto negativo en el medio ambiente que en la obtención de materiales de fuentes vírgenes. 
En ese mismo orden de ideas, en la actualidad el reciclaje de materiales es una actividad que presenta interesantes perspectivas de crecimiento, en sectores tan importantes como la construcción (Barra de Oliveira, 1996). La rápida urbanización está creando una alta demanda de materiales de construcción convencionales, para lo cual debe considerarse la disposición limitada del recurso y el consumo de energía para la producción de los materiales adoptando tecnologías amigables con el medio ambiente (Mangesh \& otros, 2013).

Ese crecimiento generado por el aumento poblacional, ha provocado un incremento en la cantidad y variedad de desechos estimulados por múltiples actividades industriales (Asokan, Mohini y Shyam, 2007), que son consecuencia de la necesidad exponencial de producción de materiales de construcción como ladrillos, cemento, agregados de acero, aluminio, madera y revestimientos (Raut, Ralegaonkar \& Mandavgane, 2011).

Son muchos los tipos de residuos que han sido estudiados en lo referente a su posible reutilización (Martínez, 1996), razón por la cual se ha comenzado a implementar la reutilización de materiales y componentes constructivos (Glinka, Vedoya \& Pilar, 2006). Precisamente existen criterios que permiten considerar la optimización de la sostenibilidad, como la funcionalidad, impacto ambiental, impacto social, impacto económico, demanda del mercado, cumplimiento de la legislación, entre otros (Van der Vorst, 2003).

Al respecto, se pretende que en la mayor cantidad de posibles industrias se implementen los sistemas sostenibles, que constituyen formas de obtener un rendimiento de los residuos, a la vez que permiten su reincorporación a los ciclos productivos, obteniendo un aprovechamiento más óptimo de los recursos naturales, minimizando el impacto sobre el medio ambiente al reducir la contaminación que generan los otros sistemas (Lecitra, 2010).

La acumulación de residuos sólidos industriales y agrícolas no tratados, especialmente en los países en desarrollo, ha dado lugar a un aumento de la preocupación ambiental. El reciclaje de tales residuos convirtiéndolos en materiales de construcción sostenibles, parece ser una solución viable no sólo al problema de la contaminación, sino también una opción económica para diseñar edificios verdes (Raut y otros, 2011).

Todas las consideraciones anteriores, fundamentan la propuesta de promover un vínculo entre las industrias regionales para explorar la posibilidad de minimización de sus residuos, lo cual se puede lograr a través del diseño de nuevos procesos productivos o modificando los existentes, para que así los residuos generados sean mínimos, reutilizando o reciclando residuos del proceso de una industria en otro proceso de otra industria (Cardona, 2007).

En el presente artículo, aplicando una propuesta de reciclaje de residuos de una industria para el proceso de otra industria (Cardona, 2007), se documenta la propuesta de investigación de una alternativa para la fabricación de ladrillos orientada a aportar a la solución de los problemas ambientales ocasionados por las prácticas artesanales de esta actividad. En dicho proceso de fabricación, se utiliza un desecho industrial proveniente de la industria del acero, sin necesidad de altas temperaturas, disminuyendo ostensiblemente el impacto ambiental en comparación con los métodos tradicionales de producción de ladrillo en la región donde se desarrolla el estudio.

Así mismo, en el trabajo de investigación se enfatiza en la evaluación del consumo energético del proceso de cocción de ladrillos en hornos artesanales con el fin de resaltar los beneficios del método propuesto en relación con emisiones, costos y eliminación del uso de combustibles no renovables, como el carbón, convirtiendo el producto en un ladrillo ecológicamente responsable.

Se evalúan las alternativas más convenientes para que se pueda implementar el proceso descrito, de manera que se conviertan en una opción real para la actividad industrial de impacto. Se describen las características principales del proceso, la forma de estructurarlo y el análisis de las variables más importantes que determinan sus verdaderas posibilidades para la generación de una opción efectiva para el sector industrial de impacto del proyecto. 


\section{METODOLOGÍA}

$\mathbf{E}$ ste estudio utiliza un enfoque de investigación cuantitativo, por tanto se fundamenta en la medición y observación de variables que posteriormente se analizan para consolidar el esquema teórico. Las variables a estudiar tienen relación con la fabricación artesanal de ladrillos, el consumo energético de la cocción de ladrillo en hornos artesanales y con la evaluación de la viabilidad técnica, ambiental y económica de la fabricación de ladrillos a partir de un residuo de la industria siderúrgica.
También se recopilan datos relacionados con la fabricación artesanal de ladrillos en la zona de los Alpes del municipio de Boyacá. De acuerdo con la clasificación de los tipos de investigación realizada por Hernández y otros (2003), este estudio propuesto es de tipo exploratorio y para su

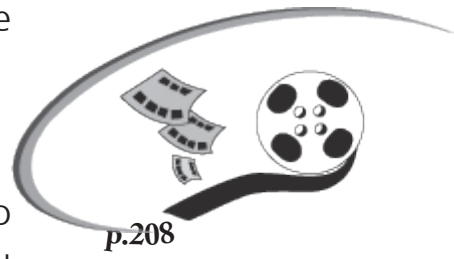
desarrollo, se emplearon instrumentos de recolección de información tales como formatos estructurados, entrevistas no estructuradas y análisis de laboratorio para diferentes minerales siguiendo las normas ASTM.

\section{DESCRIPCIÓN DE LA SITUACIÓN ACTUAL}

E I ladrillo es considerado como una unidad de mampostería, que puede tener funciones estructurales o no, y es utilizado en las edificaciones para levantamientos de muros interiores y exteriores. Se llama mampostería, al sistema tradicional de construcción que consiste en erigir muros y paramentos para diversos fines, mediante la colocación manual de los elementos o los materiales que los componen (denominados mampuestos), que pueden ser por ejemplo ladrillos cerámicos, ladrillos sílico calcáreos, ladrillos de concreto, bloques prefabricados de concreto, piedras talladas en formas regulares o no, entre otros (Arango, 2001).

Actualmente, el proceso de fabricación del ladrillo (industria de mampostería) en el departamento de Boyacá, es una actividad artesanal que se realiza siguiendo un método de trabajo con los siguientes pasos: explotación de la arcilla, preparación del fango, moldeado de los adobes (ladrillos sin cocción), secado de los adobes y cocción de los ladrillos. Estas actividades se han venido desarrollando por parte de unidades familiares que han transferido el conocimiento del proceso, de generación en generación, utilizando instalaciones artesanales que utilizan leña y carbón como combustible, denominados chircales.

Los chircales han provocado un impacto ambiental importante relacionado con la degradación y erosión de los suelos debido a las malas técnicas de explotación de la arcilla y a la tala de bosques para procurarse de la leña; además, el proceso de cocción del ladrillo es ineficiente debido a que el carbón mineral y la leña al llegar al punto de combustión, generan una gran cantidad de gases y partículas contaminantes (Maldonado, 2006). Se pueden apreciar gráficamente 
algunos de los efectos en la deforestación y erosión del suelo, así como de las emisiones de los hornos durante la cocción de ladrillos (Figura 1).
Según la Secretaría de Salud del municipio de Sogamoso (2012) la primera causa de mortalidad y morbilidad en la ciudad fueron las infecciones respiratorias agudas y las enfermedades pulmonares obstructivas crónicas, atribuibles en parte a la calidad del aire.

Figura1. Operaciones de los hornos artesanales (Chircales), Zona de los Alpes de Sogamoso



Fuente. Evidencia fotográfica recopilada por los autores.

Esta situación ha generado también condiciones de riesgo de derrumbes en áreas urbanas de la ciudad de Sogamoso, provocando niveles de contaminación que han ocasionado enfermedades e infecciones respiratorias en la población circundante a los chircales (Secretaría de Salud de Sogamoso, 2012). Lo anterior ha obligado a las entidades oficiales, como la Corporación



Autónoma de Boyacá Corpoboyacá, a ordenar el cierre de hornos de fuego dormido de producción artesanal de ladrillo (Resolución 0618 de 2013). Corpoboyacá ha estimado que en el municipio de Sogamoso

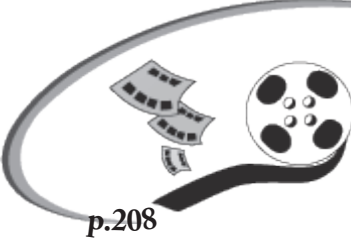
existen 403 hornos de producción de ladrillos de arcilla chircales (Figura2).

Figura 2. Hornos de fuego dormido para la cocción de ladrillos, zona de los Alpes de Sogamoso
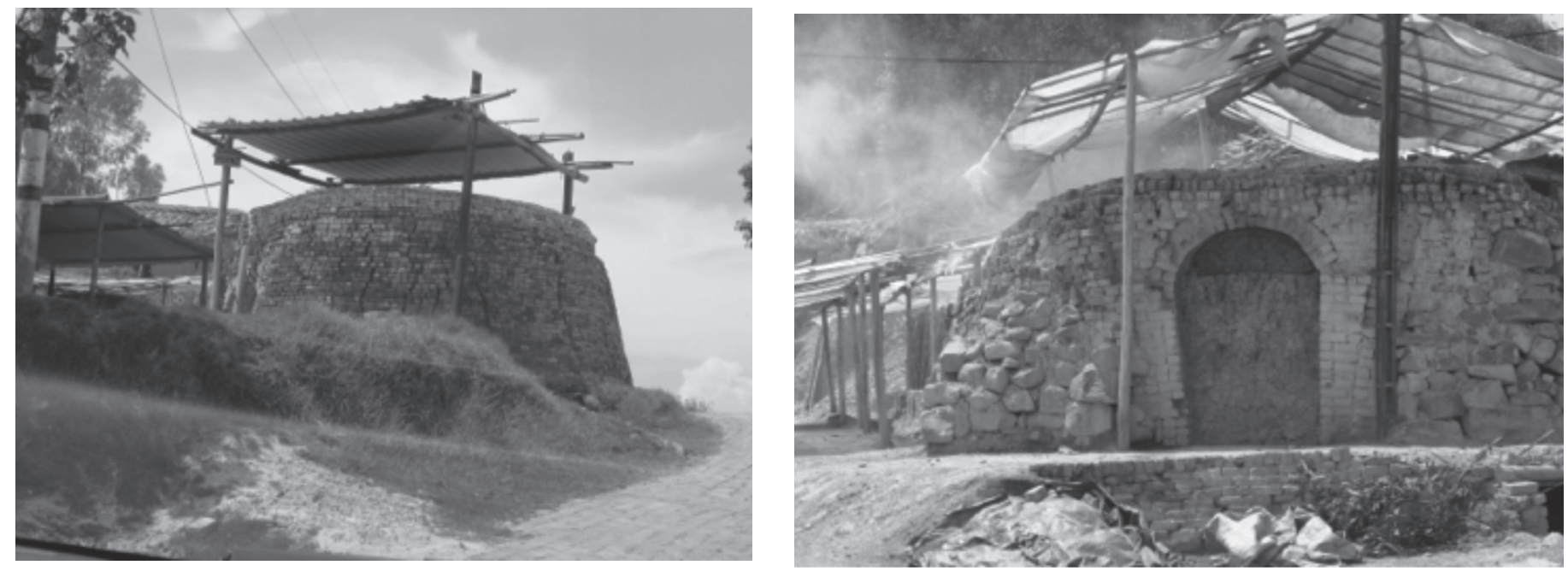

Fuente. Evidencia fotográfica recopilada por los autores. 
Por otro lado, en la ciudad de Sogamoso también se encuentra la siderúrgica más grande e importante del país, la cual genera un residuo en su proceso de producción de acero conocido como escoria. Este material se genera en forma granulada, lo cual trae consigo que partículas en suspensión sean transportadas por el aire y afecten el medio ambiente deteriorando la salud de la población de áreas circundantes. La escoria con bajo contenido de fósforo, es utilizada por las cementeras de la región, sin embargo, para escoria siderúrgica con alto contenido de fosforo, no se ha encontrado ningún uso específico, por lo cual actualmente, es dispuesto en pilas, generando costos adicionales por concepto de mantenimiento y almacenamiento.

Investigaciones recientes realizadas por la Escuela de Ingeniería Metalúrgica de la Universidad Pedagógica y Tecnológica de Colombia y la Universidad Nacional de Medellín (León, 2008), han establecido que una mezcla de escoria y cal sometida a cierta presión, puede ser utilizada para producir ladrillos silico-calcáreos con propiedades óptimas, para ser utilizados en cualquier tipo de construcción de acuerdo con la Norma Técnica Colombiana NTC 922 para unidades de mampostería, propiciando una oportunidad para aprovechar este material de desecho.

Los ladrillos que trata este proyecto, están constituidos a partir de un ecomaterial, entendiendo por ecomateriales "materiales que por su origen y composición no afectan de manera total al medio ambiente. Pueden ser de origen natural o producidos por el hombre. Su uso en el sector de la construcción, se inició formalmente hace pocos años, haciéndose más frecuente las experiencias de buenas practicas en su empleo de forma masiva en programas comerciales de construcción y conquistado un lugar en el mercado en muchos países, donde compiten con ventaja con materiales industriales. La viabilidad técnico económica de los proyectos demuestra su sustentabilidad" ${ }^{5}$.

La idea de utilizar materiales de desecho de la industria metalúrgica, no es nueva. Las mezclas que consisten en sedimentos de los puertos y de residuos de escoria de la industria del acero que contiene componentes tóxicos, se calientan para producir materiales de construcción no peligrosos (Weia \& otros, 2014). Por ejemplo, bloques huecos de mampostería de peso ligero (CHLM), fueron producidos con una mezcla de cenizas volantes, escoria, piedra pómez de perlita y cemento, y podrían ser utilizados para los bloques de hormigón en la industria de la construcción (Gunduz, 2008).

Se evaluaron algunas propiedades físicas de las probetas fabricadas con escoria de alto horno y cal hidratada, con respecto a la Norma Técnica Colombiana para cinco tipos de mezclas que varían entre el $10 \%$ y el $50 \%$ $\%$ de cal. Los resultados mostraron que es factible la fabricación de ladrillos sílico-calcáreos para mampostería que cumplen con la NTC 922 (León et al, 2009).

\footnotetext{
${ }_{5}^{5}$ Determinación de propiedades físicas y estimación del consumo energético en la producción de acero, concreto, vidrio, ladrillo y otros materiales, entre ellos los alternativos, y otros de uso no tradicional, utilizados en la construcción de edificaciones colombianas. Informe Final. Contrato entre Ecoingeniería S.A.S. y el Programa De Las Naciones Unidas Para el Desarrollo (PNUD) Proyecto GEF/PNUD/COL 70467, 2012.
} 


\section{MARCO CONTEXTUAL}

\subsection{El sector de la construcción en Colombia}

Según el Departamento Nacional de Planeación (DNP), los sectores de la economía como el mineroenergético, la construcción y la infraestructura de transporte avanzan a un mayor ritmo que los demás. Las metas del gobierno colombiano contemplan que en los próximos años las cinco locomotoras definidas dentro del Plan Nacional de Desarrollo, incrementen el crecimiento económico del país en 1,7\% por año, reduzcan la pobreza durante el periodo presidencial en $1,2 \%$ y disminuyan la tasa de desempleo en 26 puntos básicos por año.

Es así como el gobierno colombiano ha apostado por la construcción para aprovechar el incremento en la demanda de vivienda que se genera con el mayor dinamismo económico, e impulsar la generación de empleo, especialmente en las zonas urbanas del país. El sector de vivienda, dado sus eslabonamientos con múltiples y diversas actividades económicas, tiene el potencial de dinamizar la economía y promover el crecimiento y la generación de empleo de manera casi transversal. Lo anterior, sin dejar de mencionar el impacto social que implica para los hogares colombianos, contar con más y mejores condiciones de habitabilidad (León et al, 2009).

Considerando los datos publicados por el DANE, se puede afirmar que el sector de la construcción, ha sido una de las actividades productivas más dinámicas al registrar un crecimiento promedio entre 2000 y 2011 del $6.9 \%$ frente al $4.1 \%$ del PIB total, lo que se ha traducido en un aumento de su participación en la economía, pasando de representar el $4.2 \%$ en el año 2000 al $10.1 \%$ en 2011 .

El dinamismo del sector de la construcción es importante dentro de la economía nacional, teniendo en cuenta que según el informe para el 2013 del Comportamiento Sectorial, del Producto Interno Bruto (PIB) de Colombia, del Departamento Administrativo Nacional de Estadística (DANE), el sector de la construcción en Colombia creció $21,3 \%$ respecto al año inmediatamente anterior, posicionándolo como uno de los sectores mas representativos dentro del PIB. Se muestra el comportamiento trimestral del aporte al PIB del sector de la construcción a precios constantes (Figura 3).

Figura 3. Comportamiento trimestral del aporte al PIB del sector de la construcción

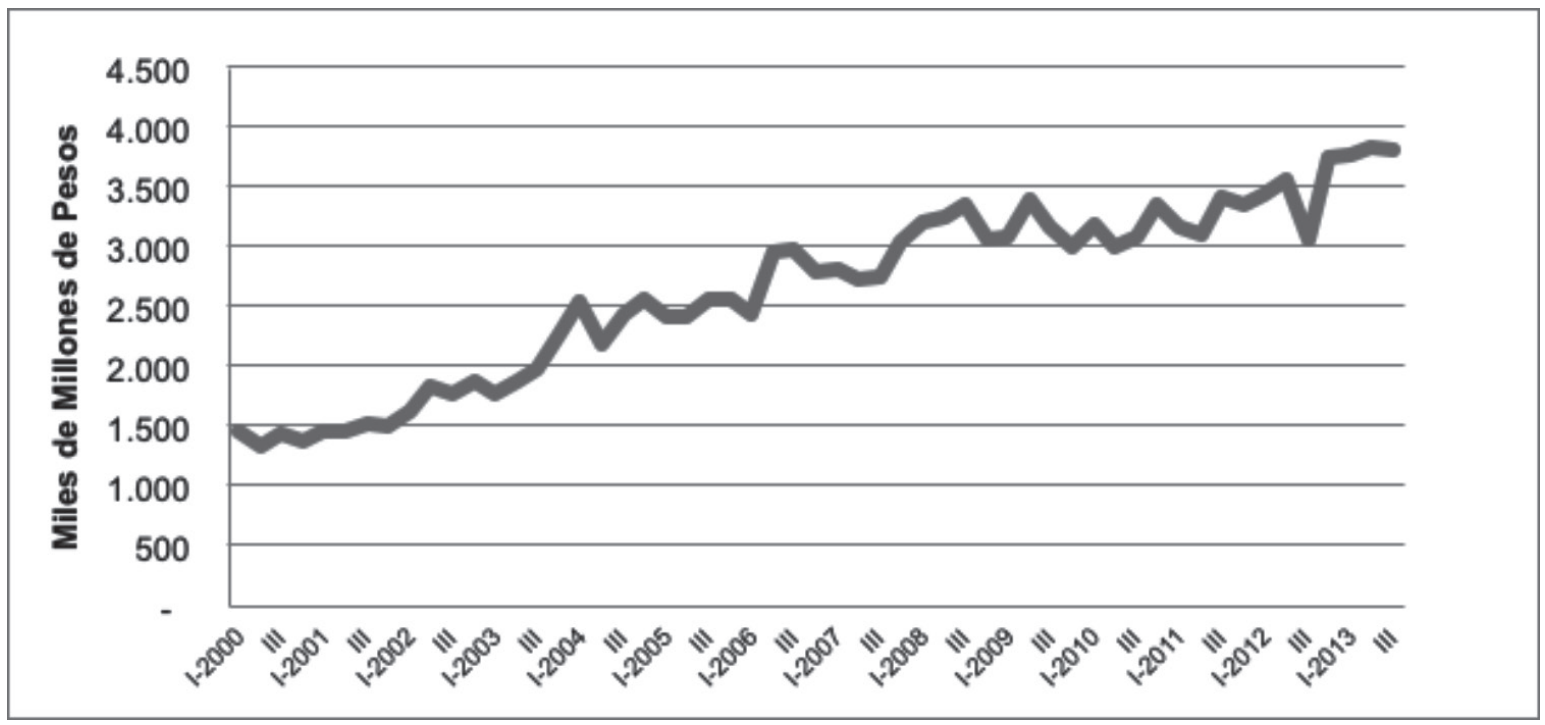

Fuente. DANE, Informe de cuentas nacionales a tercer trimestre de 2013. 
La dinámica del sector de la construcción en el departamento de Boyacá, se evidencia según los datos publicados por el DANE, (Tabla 1), en los cuales presenta el área y el número de viviendas aprobadas durante los últimos siete años. A pesar de un decline en el año 2012, la construcción durante los últimos tres años ha mantenido los mayores registros de la historia.

Tabla 1. Área aprobada $\left(\mathrm{M}^{2}\right)$ y unidades de vivienda, Boyacá*

\begin{tabular}{|c|c|c|c|c|c|c|}
\hline \multirow{2}{*}{ Año } & \multicolumn{3}{|c|}{ METROS } & \multicolumn{3}{c|}{ UNIDADES } \\
\cline { 2 - 7 } & TOTAL* & VIS** & No VIS & TOTAL* & VIS** & No VIS \\
\hline 2007 & 404.258 & 63.487 & 340.771 & 3.995 & 894 & 3.101 \\
\hline 2008 & 339.487 & 91.208 & 248.279 & 3.623 & 1.552 & 2.071 \\
\hline 2009 & 376.366 & 107.971 & 268.395 & 3.804 & 1.402 & 2.402 \\
\hline 2010 & 369.246 & 82.497 & 286.749 & 3.801 & 1.103 & 2.698 \\
\hline 2011 & 564.890 & 96.704 & 468.186 & 5.719 & 1.248 & 4.471 \\
\hline 2012 & 498.925 & 53.115 & 445.810 & 4.770 & 645 & 4.125 \\
\hline 2013 & 644.684 & 84.513 & 560.171 & 6.339 & 1.151 & 5.188 \\
\hline & & & & & & \\
\hline
\end{tabular}

*Principales centros urbanos: Tunja, Duitama, Sogamoso, Chiquinquirá.

Fuente. DANE, 2013.

\subsection{Descripción de la fabricación artesanal de ladrillos en Boyacá}

La alfarería en Sogamoso, es una actividad que lleva más de cien años y en la cual se producen ladrillos y tejas. Sogamoso es el principal centro de producción artesanal de ladrillo en Boyacá, debido a la abundancia y facilidad para conseguir la arcilla, la materia prima. El carbón y la madera son utilizados como combustibles en los hornos, sin dejar de mencionar la falta de planes de ordenamiento territorial y los pocos controles ambientales que se realizaban (Buitrago \& Salazar, 2013).

Estas condiciones propiciaron que muchas familias de la región de escasos recursos, vieran en la instalación de hornos artesanales para fabricar ladrillos y tejas, una oportunidad para garantizar su subsistencia, tanto así que para el año 2013 dependían de esta actividad 273 familias, participando 370 niños con edades entre cinco y siete años, en las labores del proceso productivo (Sarmiento, 2006).

El censo de actividades económicas realizado por la Alcaldía de Sogamoso, ha establecido que en el valle de Sogamoso se localizan 403 hornos de producción de ladrillo activos y 47 inactivos, al igual que 178 hornos de cal en los municipios de Nobsa, Firavitoba y Tibasosa. Lo anterior, ha ubicado al municipio como el cuarto corredor industrial con mayor generación de emisiones atmosféricas de material particulado (PM-10) del país después de grandes ciudades como Bogotá, Medellín y la ciudadela industrial de Norte de Santander ${ }^{6}$.

\footnotetext{
${ }^{6}$ Para ampliar esta información consultar la Ficha Regional Sogamoso. Ministerio de Industria, Comercio y Turismoo Sanitario Doña Juana.
} 
Estas condiciones de producción artesanal de ladrillo, utilización de combustibles provenientes de recursos no renovables, explotación de minerales sin tener en cuenta criterios técnicos, empleo de mano de obra infantil y contaminación ambiental, han provocado que las autoridades medio ambientales del departamento de Boyacá como Corpoboyacá, tomaran la decisión de emitir el pasado 30 de abril de 2013 la Resolución 0618, que determina, entre otras cosas, el cierre definitivo y la demolición de los hornos artesanales de cocción de cal y arcilla que se encuentren ubicados en zonas cuyo uso de suelo no lo permita?.

\subsection{El proceso de fabricación artesanal de ladrillos en Boyacá}

A continuación se muestran las diferentes operaciones realizadas dentro del proceso de fabricación artesanal de ladrillo en la región del Valle de Sogamoso.

Tabla 2. Descripción del proceso artesanal de fabricación de ladrillos cerámicos

\begin{tabular}{|l|l|}
\hline \multicolumn{1}{|c|}{ Operación } & \multicolumn{1}{c|}{ Descripción } \\
\hline Explotación de la arcilla & $\begin{array}{l}\text { Se extrae la arcilla de la cantera utilizando generalmente } \\
\text { pica y pala, y en otros casos maquinaria pesada. }\end{array}$ \\
\hline Preparación del fango. & $\begin{array}{l}\text { Eliminar los terrones de arcilla, manteniendo una } \\
\text { granulometría fina y adicionar agua a la arcilla hasta } \\
\text { obtener un fango homogéneo. }\end{array}$ \\
\hline Moldeado de adobes. & Se cortan los ladrillos en el fango. \\
\hline Secado de adobes & Dejar secar los adobes al medio ambiente. \\
\hline Cargado del horno & Llevar los adobes al interior del horno. \\
\hline Preparación de la quema & Iniciar el calentamiento del horno. \\
\hline Cocción de ladrillos & Mantener temperatura del horno entre $800^{\circ}$ y $900^{\circ} \mathrm{C}$. \\
\hline Descargado del horno & Sacar los ladrillos del horno \\
\hline Almacenamiento de ladrillos & Mantener lo ladrillos en patio hasta su entrega al cliente. \\
\hline
\end{tabular}

Fuente. Elaboración propia de los autores.

\subsubsection{Energía requerida para el proceso}

Algunos de los problemas ambientales mas importantes generados por la fabricación artesanal de ladrillos, se presenta en el proceso de cocción, debido a que la combustión del carbón térmico genera gases de efecto invernadero y cenizas que en forma de material particulado afectan el aire (Figura 4). Durante este proceso, los adobes de arcilla amasada entran al horno, pierden humedad y sufren transformaciones fisicoquímicas, para obtener ladrillos cerámicos sólidos. La cocción tiene una duración promedio de 13 días, los primeros cuatro días corresponden a la quema y los nueve restantes corresponden al enfriamiento del horno. Las fuentes de energía utilizadas son el carbón térmico para iniciar el horno y el coque para finalizar la quema. A continuación se presenta la caracterización de los combustibles empleados, con el objetivo de establecer el consumo de energía y el costo actual energético del proceso de cocción:

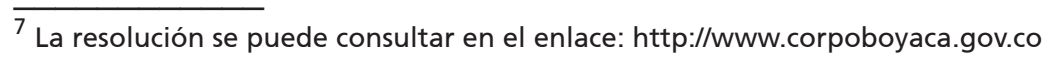


Figura 4. Cocción de ladrillos en la zona de los Alpes, Sogamoso

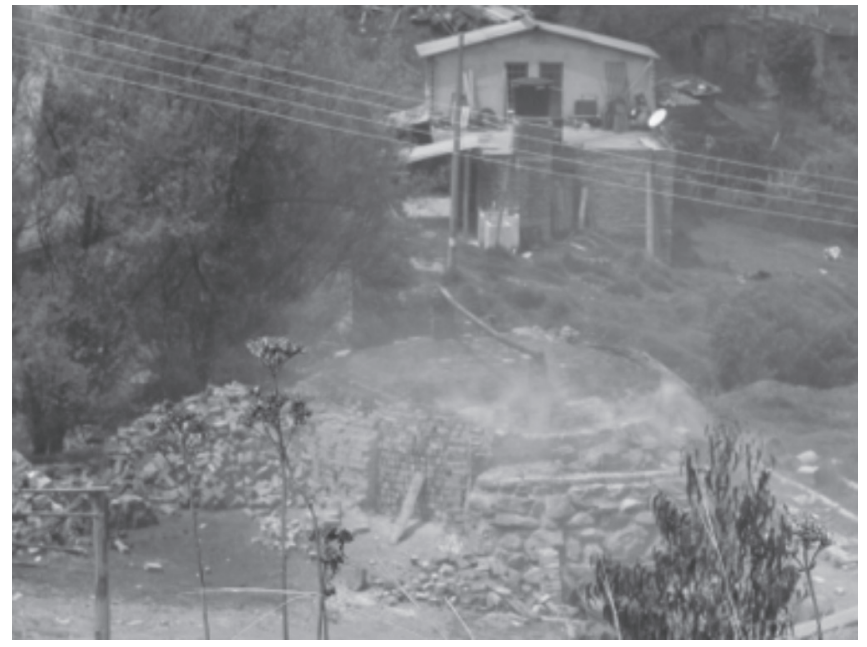

Fuente. Evidencia fotográfica recopilada por los autores.

\subsubsection{Combustibles empleados}

Los combustibles empleados son el carbón térmico y el coque. En cada centro de producción artesanal se tomó una muestra de carbón de $4 \mathrm{~kg}$, de cada tipo de carbón y se determinaron sus características físico-químicas, mediante los análisis próximos o inmediatos que incluyen la cuantificación de la humedad residual, materia volátil, azufre, cenizas, carbono fijo, poder calorífico e índice de hinchamiento (Ecocarbón, s.f.). Se describen de manera general cada uno de estos componentes:

La humedad: el agua siempre se encuentra en contacto con el carbón en dos formas: humedad libre que es la humedad externa del carbón y se liga a esta por medio de la tensión superficial, y la humedad inherente o residual.

Las cenizas: corresponde al porcentaje de residuo orgánico que queda luego de la combustión de la muestra.

La materia volátil: se convierte en un parámetro importante de clasificación y equivale a la cantidad de gases presentes en el carbón.

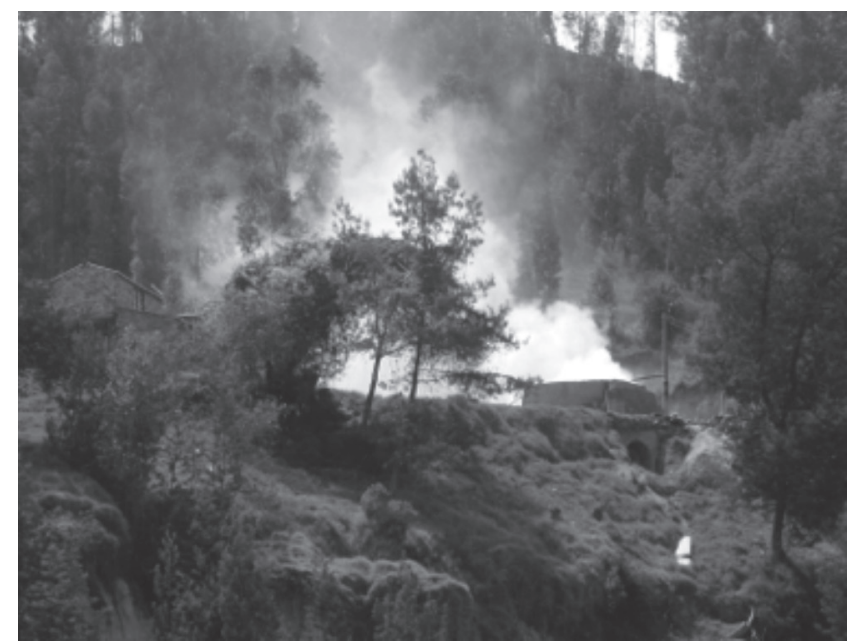

El carbono fijo: representa la porción combustible del carbón y se obtiene por diferencia, restando de 100 los porcentajes de humedad, cenizas y materia volátil.

El azufre: su presencia incide de manera importante en la calidad del carbón, de ahí que su resultado es muy importante. El azufre hace presencia en todos los carbones ya sea en forma orgánica, inorgánica y comúnmente en forma de sulfuros (pirita y marcasita).

Cada muestra se maceró en un mortero, se cuarteó y se llevó a una molienda en un molino centrífugo de bolas s-1000 RETSCH; posteriormente, se hizo pasar por una malla 60. El Análisis Humedad Residual se realizó de acuerdo con lo establecido en la norma ASTM D3173, el Análisis Humedad Total según la norma ASTM D 3302 y el poder Calorífico de acuerdo con la Norma D5865. Todos estos análisis se realizaron para las muestras tomadas en cada uno de los 20 hornos en el laboratorio de carbones de la Universidad Pedagógica y Tecnológica de Colombia (Tabla 3). 
Tabla 3. Resultados analíticos promedio para las muestras de carbón.

\begin{tabular}{|l|l|l|l|l|l|l|l|l|}
\hline Carbón & $\begin{array}{c}\text { Humedad } \\
\text { Residual } \\
(\%)\end{array}$ & $\begin{array}{c}\text { Humedad } \\
\text { Libre (\%) }\end{array}$ & $\begin{array}{c}\text { Humedad } \\
\text { Total (\%) }\end{array}$ & $\begin{array}{c}\text { Cenizas } \\
(\%)\end{array}$ & $\begin{array}{c}\text { Materia } \\
\text { Volátil } \\
(\%)\end{array}$ & $\begin{array}{c}\text { C. Fijo } \\
(\%)\end{array}$ & $\begin{array}{c}\text { Poder } \\
\text { Calorífico } \\
(\text { Cal/gr) }\end{array}$ & $\begin{array}{c}\text { Azufre } \\
(\%)\end{array}$ \\
\hline Térmico & 7.25 & 2.32 & 8.88 & 11.39 & 26.65 & 57.71 & 5.980 & 0.65 \\
\hline Coque & 1,01 & 0,56 & 1,57 & 7,8 & 2,07 & 89,71 & 7.180 & 0,42 \\
\hline
\end{tabular}

Fuente. Resultados de laboratorio de carbones.

\subsubsection{Análisis calórico}

Los datos usados en este cálculo son un promedio de la consulta hecha de 20 hornos de la zona de los Alpes en Sogamoso (Boyacá), con una capacidad promedio de 32.000 unidades de ladrillo, en donde se utilizan como fuentes de energía el carbón térmico para iniciar el horno y el coque para finalizar la quema.

Tabla 4. Fuentes de energía utilizadas para la cocción de ladrillos en hornos artesanales.

\begin{tabular}{|c|l|l|l|l|}
\hline $\begin{array}{c}\text { Capacidad Horno } \\
\text { (unidades) }\end{array}$ & \multicolumn{1}{|c|}{ Combustible } & $\begin{array}{c}\text { Cantidad Utilizada } \\
(\mathbf{k g})\end{array}$ & Precio (COP/Kg) & $\begin{array}{c}\text { Poder Calorífico } \\
\text { (kcal/kg) }\end{array}$ \\
\hline 32.000 ladrillos & Carbón Térmico & 2.000 & 150 & 5.980 \\
\hline & Coque & 5.000 & 203 & 7.200 \\
\hline
\end{tabular}

Fuente. Elaboración propia de los autores.

Se considera como unidad de producción, un ladrillo macizo de arcilla cocida con dimensiones aproximadas de $20 \mathrm{~cm} \times 10 \mathrm{~cm} \times 7 \mathrm{~cm}$ (volumen $\left.=1.400 \mathrm{~cm}^{3}\right)$, con una masa promedio de $2.6 \mathrm{~kg}$ y cuya densidad es 1,86 $\mathrm{g} / \mathrm{cm}^{3}$.

La energía que aporta el carbón térmico al horno (QCT) es de:

$$
\begin{aligned}
& Q_{C T}=2.000 \mathrm{~kg} \times 5.980 \mathrm{kcal} / \mathrm{kg} \text {, luego, } Q_{C T}=11,96 \times 10^{6} \mathrm{kcal} \\
& \text { La energía que aporta el carbón coque al horno } \\
& \left(\mathrm{Q}_{c \mathrm{cC}}\right) \text { es de: } \\
& \mathrm{Q}_{c \mathrm{CC}}=5.000 \mathrm{~kg} \times 7.200 \mathrm{kcal} / \mathrm{kg} \text {, luego, } \mathrm{Q}_{c \mathrm{C}}=36 \times 10^{6} \mathrm{kcal}
\end{aligned}
$$

Entonces, la energía total que aportan el carbón térmico y el carbón coque al horneado del lote de ladrillo es de:

$$
\mathrm{Q}=\mathrm{Q}_{\mathrm{CT}}+\mathrm{Q}_{\mathrm{CC}}=47,96 \times 10^{6} \mathrm{kcal}
$$

De tal forma que la energía consumida por unidad de ladrillo producido es de:

$47,96 \times 10^{6} \mathrm{kcal} / 32.000$ unidades $=1.499 \mathrm{kcal} /$ unidad

Y la energía consumida por kg de ladrillo es de:

$$
(1.499 \mathrm{kcal} / \mathrm{unidad}) \times(1 \mathrm{unidad} / 2.6 \mathrm{~kg}) \approx 577 \mathrm{kcal} / \mathrm{kg}
$$

A continuación se esquematiza el cálculo del consumo calorífico en el proceso de cocción de ladrillos (Figura 5). 
Figura 5. Determinación de la energía requerida en el proceso de cocción de ladrillos

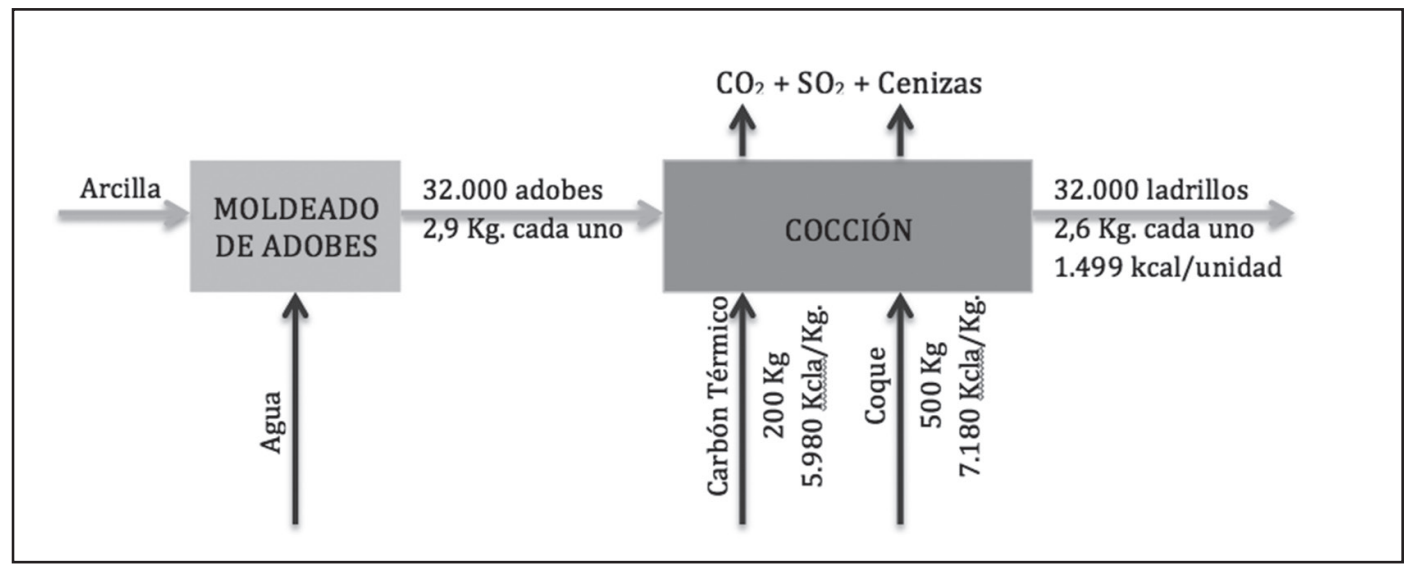

Fuente. Elaboración propia de los autores.

También, se calcula el costo energético de cocción de los 32.000 ladrillos:

$$
(2.000 \mathrm{Kg} \times \mathrm{COP} 150 / \mathrm{Kg})+(5.000 \times \mathrm{COP} 230 / \mathrm{Kg})=\mathrm{COP} 1.450 .000
$$

Por lo tanto, el costo energético por cada ladrillo producido es de:

$$
\text { COP1.450.000/32.000 unidades }=\text { COP45.3/unidad, }
$$

Finalmente, el costo energético por kilogramo de ladrillo es:

$$
\text { COP45.3 } / 2.5 \mathrm{~kg}=\mathrm{COP} 18.12 / \mathrm{kg}
$$

Los ladrillos producidos por este método, en promedio se venden a $\$ 250$ cada uno, por lo tanto, tan solo el consumo calórico del proceso de cocción representa el 18,12\% del costo total de fabricación (Figura 6)

Figura 6. Determinación del costo de la energía requerida en el proceso de cocción de ladrillos

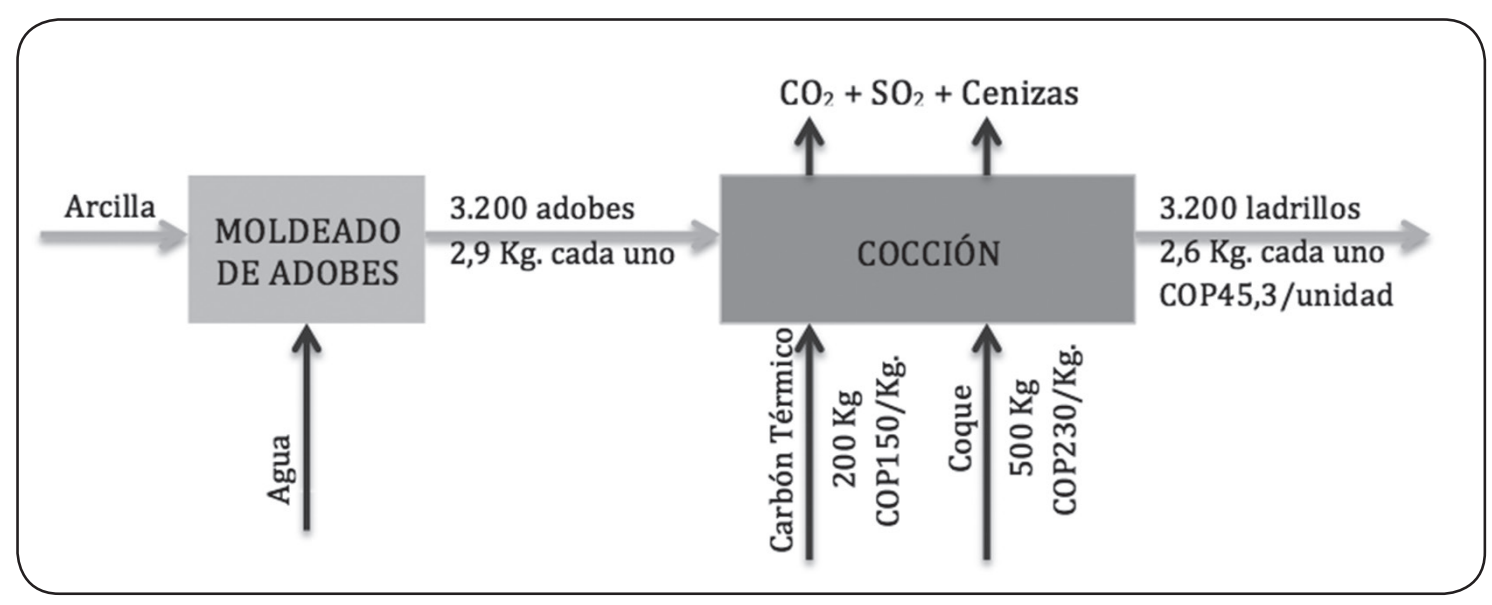

Fuente. Elaboración propia de los autores. 


\section{ANÁLISIS Y RESULTADOS DEL PROYECTO: PROCESO DE FABRICACIÓN DE LADRILLOS ECOLÓGICOS A ESCALA INDUSTRIAL}

onsiderando los problemas ambientales y los altos costos generados en el proceso de cocción para producir ladrillos de forma artesanal, se considera el método alternativo propuesto en León, \& otros (2009), para lo cual se utilizó como materias primas escoria de alto horno de la industria del acero y cal hidratada, dos materiales de gran abundancia en la región del Valle de Sogamoso. La mezcla se hidrató y se sometió a una presión de $300 \mathrm{kgf} / \mathrm{cm}^{2}$, luego se formaron los ladrillos y se sacaron a medio ambiente durante diez días.

\subsection{Materiales a utilizar}

Una de las materias primas a utilizar, corresponde a la escoria separada en el proceso de fabricación de arrabio en la industria del acero. La presentación del material es granulada y de acuerdo con los resultados de laboratorio, a su granulometría corresponde un $\mathrm{d}_{80}$ entre 2,15 mm y 1,06 mm. La composición química, corresponde a lo esperado para escorias siderúrgicas (Tabla 5) (Mclean, 2004).

Tabla 5. Composición química de la escoria de alto horno

\begin{tabular}{|l|l|l|l|l|l|l|l|l|}
\hline $\mathrm{CaO}$ & $\mathrm{SiO}_{2}$ & $\mathrm{Al}_{2} \mathrm{O}_{3}$ & $\mathrm{P}$ & $\mathrm{Na}_{2} \mathrm{O}$ & $\mathrm{MgO}$ & $\mathrm{Fe}_{2} \mathrm{O}_{3}$ & $\mathrm{Fe}$ & $\mathrm{K}_{2} \mathrm{O}$ \\
\hline 40,84 & 27,32 & 14,91 & 3,30 & 1,95 & 1,35 & 0,82 & 0,43 & 0,12 \\
\hline
\end{tabular}

Fuente. Resultados de análisis de laboratorio.

La otra materia prima es la cal hidratada, empleada en procesos agroindustriales y fabricada en el municipio de Nobsa (Boyacá). A continuación se muestra la composición química de la cal (Tabla 6).

Tabla 6. Composición química de la escoria de alto horno

\begin{tabular}{|l|l|l|l|l|l|l|}
\hline $\mathrm{CaO}$ & $\mathrm{SiO}_{2}$ & $\mathrm{Al}_{2} \mathrm{O}_{3}$ & $\mathrm{MgO}$ & $\mathrm{Fe}_{2} \mathrm{O}_{3}$ & $\mathrm{PPC}$ & Reactividad \\
\hline 75,1 & 10,2 & 1,5 & 0,8 & 6,5 & 5,25 & 286 \\
\hline
\end{tabular}

Fuente. Resultados de análisis de laboratorio.

\subsection{Conformación de la mezcla}

De acuerdo con lo expuesto en León y otros (2009), en la mezcla al $20 \%$ de cal, la escoria actúa como agregado, mientras que la cal actúa como cementante. Según las pruebas realizadas en laboratorio, la mezcla con $20 \%$ de cal hidratada y $80 \%$ de escoria fina, cumple con los parámetros establecidos en la norma
NTC 922 para ladrillos sílico-calcáreos, para los ensayos de compresión, obteniendo 108,3 kgf/ $\mathrm{cm}^{2}$ frente a 80 $\mathrm{kgf} / \mathrm{cm}^{2}$ de la norma; absorción de agua con $13.8 \%$ en comparación con un máximo de $20 \%$ establecido por la norma y de sismorresistencia. 


\subsection{Proceso propuesto}

Utilizando estos materiales, se propone la implementación de un proceso para producir estos ladrillos ecológicos a escala industrial y la descripción de las operaciones del proceso, además de los activos necesarios (Figura 7 y Tabla 7).

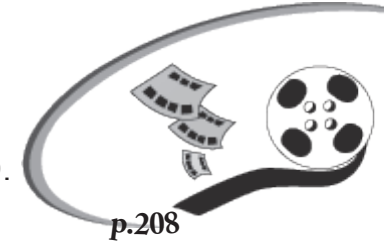

Figura 7. Proceso propuesto para fabricar ladrillos a partir de residuos de la ilndustria del acero

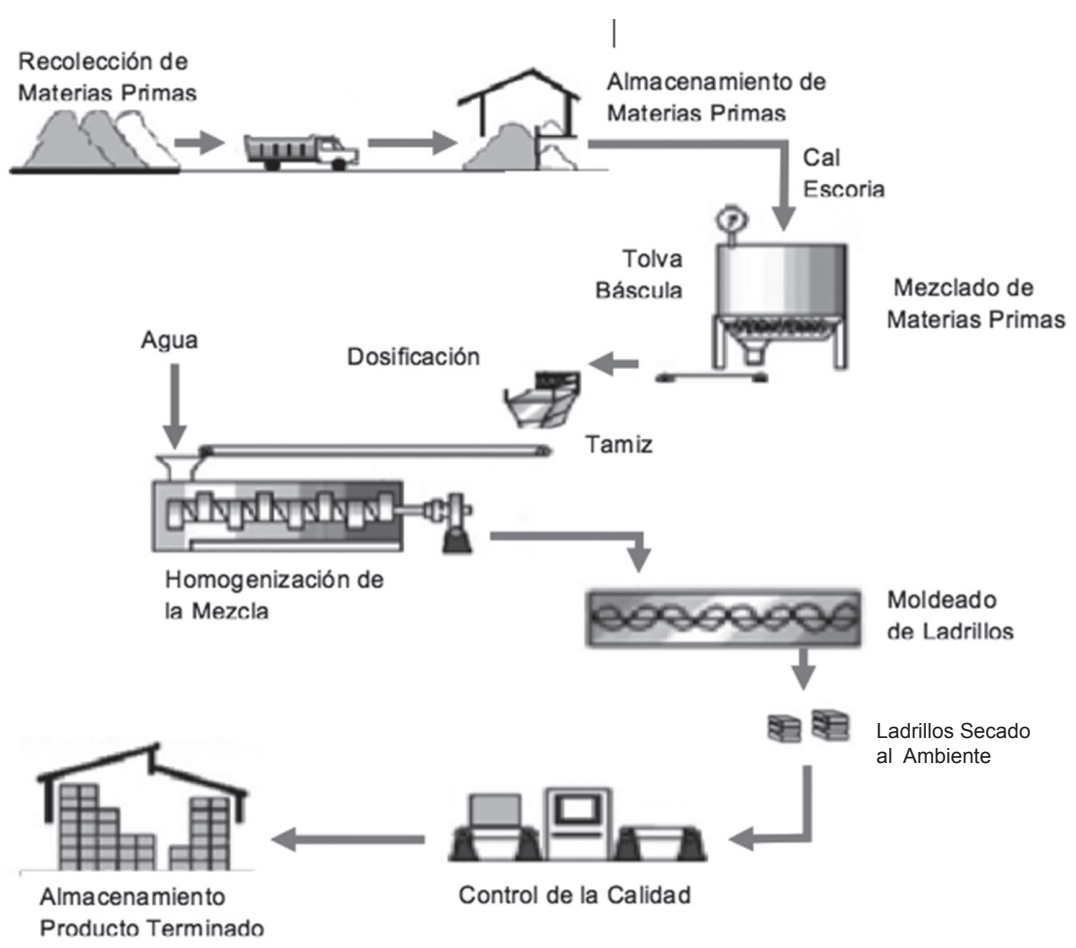

Fuente. Elaboración propia de los autores. 
Tabla 7. Descripción proceso propuesto para producir ladrillos ecológicos.

\begin{tabular}{|l|l|l|}
\hline \multicolumn{1}{|c|}{ Operación } & \multicolumn{1}{|c|}{ Descripción } & \multicolumn{1}{|c|}{ Equipos / Infraestructura } \\
\hline Almacenar materia prima & $\begin{array}{l}\text { La escoria y la cal se transportan en } \\
\text { volquetas y se almacenan cubiertas } \\
\text { en patio. La escoria se debe someter } \\
\text { a un proceso de molienda para } \\
\text { controlar su granulometría. }\end{array}$ & $\begin{array}{l}\text { Almacén de materias primas. } \\
\text { Molino. }\end{array}$ \\
\hline Mezclar materias primas & $\begin{array}{l}\text { Las materias primas se mezclan en } \\
\text { tolvas en la proporción establecida. }\end{array}$ & $\begin{array}{l}\text { Tolva. } \\
\text { Báscula. } \\
\text { Tornillo sinfín. }\end{array}$ \\
\hline Preparar masa & $\begin{array}{l}\text { Se adiciona agua a la mezcla en la } \\
\text { tolva y se homogeniza, luego se } \\
\text { transporta mediante tornillo sinfín a }\end{array}$ & $\begin{array}{l}\text { Dosificador. } \\
\text { Criba }\end{array}$ \\
Tornillo sinfín. \\
\hline la extrusora.
\end{tabular}

Fuente. Elaboración propia de los autores.

\subsection{Evaluación económica del proyecto}

Con el fin de respaldar las viabilidades técnica y ambiental del proceso propuesto, a continuación se presenta una evaluación económica del proyecto de inversión, teniendo en cuenta que las materias primas son de fácil adquisición y que en el caso de la escoria de alto horno, al ser un desecho industrial, es de bajo costo y además, considerando las siguientes variables:

\subsubsection{Mercado}

Se plantea atender un mercado regional enfocado a las principales ciudades del departamento de Boyacá, tales como Tunja, Duitama, Sogamoso, Chiquinquirá y Guateque. Se muestran los datos publicados por el DANE con respecto a la dinámica constructora en el departamento Boyacá en términos de unidades de edificaciones y de metros cuadrados licenciados, comprobando que las condiciones económicas y políticas de los últimos han generado resultados favorables en la construcción. En promedio, el 20\% de los metros cuadrados de construcción aprobados corresponde a Viviendas de Interés Social (VIS) y representan en promedio, el $26 \%$ de las unidades habitacionales en el departamento durante los últimos siete años (Tabla 8). 
Tabla 8. Área aprobada $\left(\mathrm{m}^{2}\right)$ y unidades de vivienda, Boyacá*

\begin{tabular}{|c|l|l|l|l|l|l|}
\hline & \multicolumn{3}{|c|}{ METROS } & \multicolumn{3}{c|}{ UNIDADES } \\
\hline AÑO & \multicolumn{1}{|c|}{ TOTAL* $^{*}$} & \multicolumn{1}{|c|}{ VIS** $^{*}$} & \multicolumn{1}{|c|}{ No VIS } & \multicolumn{1}{|c|}{ OOTAL* $^{*}$} & \multicolumn{1}{|c|}{ VIS* $^{*}$} & No VIS \\
\hline 2007 & 404.258 & 63.487 & 340.771 & 3.995 & 894 & 3.101 \\
\hline 2008 & 339.487 & 91.208 & 248.279 & 3.623 & 1.552 & 2.071 \\
\hline 2009 & 376.366 & 107.971 & 268.395 & 3.804 & 1.402 & 2.402 \\
\hline 2010 & 369.246 & 82.497 & 286.749 & 3.801 & 1.103 & 2.698 \\
\hline 2011 & 564.890 & 96.704 & 468.186 & 5.719 & 1.248 & 4.471 \\
\hline 2012 & 498.925 & 53.115 & 445.810 & 4.770 & 645 & 4.125 \\
\hline 2013 & 644.684 & 84.513 & 560.171 & 6.339 & 1.151 & 5.188 \\
\hline
\end{tabular}

*Principales centros urbanos: Tunja, Duitama, Sogamoso, Chiquinquirá.

Fuente. DANE, 2013.

Se ilustra el comportamiento histórico reciente de la construcción de nuevas viviendas en las principales ciudades del departamento de Boyacá, en donde se aprecia que en los últimos tres años las unidades habitacionales NO VIS, han registrado los mejores niveles con tendencia al aumento. En cuanto a las VIS, se pude observar que han tenido un comportamiento relativamente estable, sin embargo las políticas nacionales en esta materia, se orientan también al incremento de este tipo de viviendas (Figura 8).

Figura 8. Comportamiento nuevas unidades de vivienda, departamento Boyacá.

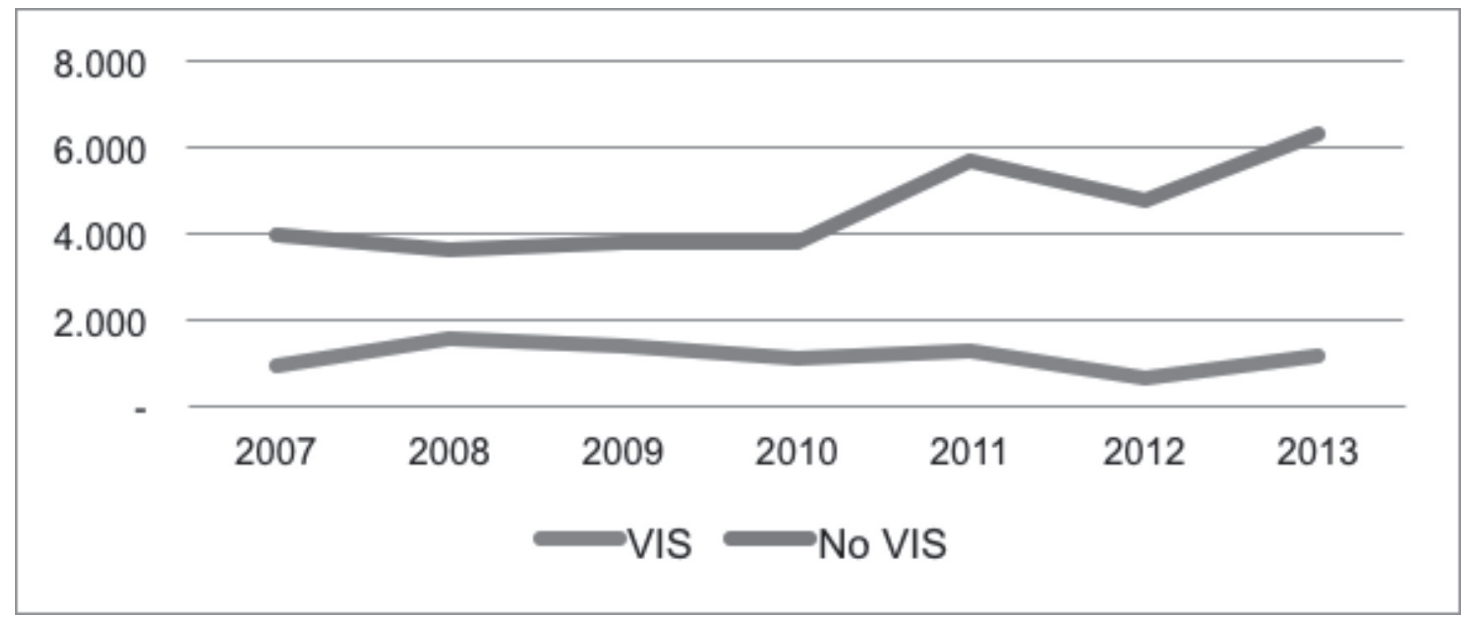

Fuente. Elaboración propia de los autores, a partir de datos publicados por el DANE.

Lo expuesto anteriormente, muestra un muy buen panorama del comportamiento de la construcción de unidades habitacionales en el departamento de Boyacá, favoreciendo la producción de artículos necesarios para desarrollar esta actividad, tales como las unidades de mampostería.

Para trasladar estos datos dados en número de nuevas viviendas, a unidades de ladrillos, se tiene en cuenta el estudio realizado para la Asociación Industrial y Tecnológica Arcillas Sugamuxi, por parte del grupo de investigación Observatorio, de la Escuela de Ingeniería Industrial de la Universidad Pedagógica, en donde gracias a un estudio estadístico a las construcciones realizadas en el departamento de Boyacá durante los últimos años, se concluyó que en promedio se requieren 8.000 ladrillos por cada vivienda (Buitrago y Salazar, 2007). El mismo estudio determinó que la cuota de mercado de los ladrillos cerámicos provenientes de fabricación artesanal, es del 16,20\%. 
Para estimar el crecimiento del mercado se parte de la hipótesis de que el aumento de las unidades habitacionales se encuentra directamente correlacionada con el crecimiento de los hogares, asumiendo que se mantendría el déficit habitacional actual. Este razonamiento lo ha considerado el DANE y sus expertos han proyectado hasta el año 2.020 el crecimiento tanto de hogares como de viviendas ${ }^{8}$ (Tabla 9).
Para la proyección del mercado, se calcula el crecimiento porcentual anual de las viviendas y partiendo del mercado de ladrillos en el departamento de Boyacá calculado para el 2013, de 50.712.000 ladrillos, se proyecta el tamaño del mercado para los próximos siete años.

Tabla 9. Proyección del mercado de ladrillos en Boyacá*

\begin{tabular}{|l|l|l|l|l|l|l|}
\hline & 2013 & 2014 & 2015 & 2016 & 2017 & 2018 \\
\hline Hogares & 371.549 & 375.994 & 380.316 & 385.280 & 389.930 & 394.336 \\
\hline Viviendas & 390.333 & 395.136 & 399.785 & 405.087 & 410.042 & 414.728 \\
\hline Crecimiento Porcentual de Viviendas & & $1,23 \%$ & $1,18 \%$ & $1,33 \%$ & $1,22 \%$ & $1,14 \%$ \\
\hline Proyección Mercado de Ladrillos** & 50.712 & 51.336 & 51.940 & 52.629 & 53.273 & 53.881 \\
\hline
\end{tabular}

*Principales centros urbanos (Tunja, Duitama, Sogamoso, Chiquinquirá).

** Cifras en miles de unidades de ladrillos.

Fuente. Elaboración propia a partir de los datos publicados por el DANE.

Se puede concluir que considerando la simple dinámica del crecimiento poblacional, el mercado de ladrillos en el departamento de Boyacá presenta perspectivas de expansión. Con el propósito de seguir manteniendo un enfoque conservador en la cifras, no se van a considerar en las proyecciones factores adicionales de crecimiento que se pudieran generar, producto de los efectos de las políticas nacionales para apoyar al sector de la construcción.

\subsubsection{Capex}

Las inversiones necesarias están representadas en el terreno, edificaciones, maquinaria y equipos, y capital de trabajo operativo y se han estimado en 1.950 millones de pesos.

\subsubsection{Ingresos y costos}

Se considera que se podría tener una cuota de mercado del $17 \%$ y que los ladrillos se podrían vender en 400 pesos la unidad, un $20 \%$ menos al ofrecido por empresas ladrilleras legalmente constituidas y tecnificadas. El resumen de costos unitarios de producción y de gastos se muestra a continuación (Tabla 10).

\footnotetext{
${ }_{8}$ Para ampliar esta información, consultar: http://dane.gov.co/index.php/poblacion-y-demografia/proyecciones-de-poblacion.
} 
Tabla 10. Estructura proyectada de costos y gastos

\begin{tabular}{|c|c|c|c|}
\hline TIPO & DESCRIPCIÓN & $\begin{array}{l}\text { COSTO UNITARIO } \\
\text { (COP) }\end{array}$ & $\begin{array}{l}\% \text { CON RELACIÓN AL } \\
\text { PRECIO DE VENTA }\end{array}$ \\
\hline Costo material directo & Escoria de alto horno & 80 & $20,0 \%$ \\
\hline Costo material directo & Cal hidratada & 29 & $7,2 \%$ \\
\hline Costo material directo & Aditivo & 16 & $4,0 \%$ \\
\hline Costo material directo & Colorante & 5 & $1,2 \%$ \\
\hline $\begin{array}{c}\text { TOTAL COSTO UNITARIO } \\
\text { MATERIAL DIRECTO } \\
\end{array}$ & 130 & $32,4 \%$ & \\
\hline MANO DE OBRA DIRECTA & Operarios & 7,34 & $1,8 \%$ \\
\hline Costos indirectos fabricación & Mantenimiento, insumos & 17,78 & $4,4 \%$ \\
\hline \multicolumn{2}{|c|}{ COSTO TOTAL UNITARIO DE PRODUCCION } & 155 & $39 \%$ \\
\hline $\begin{array}{l}\text { GASTOS ANUALES PERSONAL } \\
\text { ADMINISTRACION Y VENTAS }\end{array}$ & $\mathrm{COP}$ & \multicolumn{2}{|c|}{136.197 .000} \\
\hline $\begin{array}{l}\text { GASTOS ANUALES DE } \\
\text { PROMOCION Y VENTAS }\end{array}$ & COP & \multicolumn{2}{|c|}{120.000 .000} \\
\hline
\end{tabular}

Fuente. Elaboración propia de de los autores.

\subsubsection{Flujo neto de efectivo}

Con una tasa impositiva del 33\%, se obtiene un flujo neto de efectivo, para cinco años de análisis y cifras en millones de pesos colombianos (COP) (Figura 9).

Figura 9. Flujo neto de efectivo



Fuente. Elaboración propia de los autores.

La tasa interna de retorno del proyecto es del $36 \%$, por lo que se puede afirmar que para un escenario conservador de participación en el mercado, la fabricación de ladrillos ecológicos, a partir de la mezcla de un residuo de la industria del acero y cal hidratada, es económicamente viable. 


\section{CONCLUSIONES}

$\mathrm{E}$ n el presente artículo, se ha documentado la propuesta para el proyecto de implementación de una alternativa para la fabricación de ladrillos orientada a aportar a la solución de los problemas ambientales ocasionados por las prácticas artesanales de esta actividad. Dicha propuesta vincula los desechos de una industria como la siderúrgica, para mejorar la actividad de otra industria como la mampostería en el departamento de Boyacá.

El sector de la construcción es uno de los que más ha aportado al desarrollo económico del país durante los últimos años, en gran medida debido al comportamiento de las tasas de interés preferenciales para los créditos hipotecarios y a los programas de subsidio a viviendas para familias de escasos recursos. Esto ha originado una demanda creciente de todos los productos asociados a esta actividad, como los ladrillos.

En la región del Valle de Sogamoso, la fabricación artesanal de ladrillos cerámicos ha venido generando problemas ambientales relacionados con la erosión, deforestación, emisión de gases de efecto invernadero y contaminación del aire por material particulado.

Esta situación crea unas condiciones propicias para la implementación de un proceso de producción de ladrillos alternativo. Se ha comprobado que técnicamente es viable la fabricación de estos productos silico-calcáreos a partir de una mezcla de escoria de alto horno y cal hidratada (León et al, 2009).

El proceso propuesto, no requiere de altas temperaturas, por lo tanto es favorable con respecto al artesanal en lo relacionado con la protección del medio ambiente, debido a que no genera emisiones contaminantes, elimina los requerimientos de energía de casi $1.500 \mathrm{kcal}$ por ladrillo y no utiliza combustibles provenientes de recursos naturales no renovables como el carbón y el coque.

Desde el punto de vista económico, el proceso propuesto presenta algunas ventajas debido a que la materia prima principal, es un material de desecho de muy bajo costo y que al no requerir de hornos de cocción de ladrillos, tiene una diferencia comparativa de 45 pesos por unidad, en los costos de producción.

Además de su viabilidad ambiental y técnica, el proyecto de fabricación de ladrillos reciclando residuos de la industria del acero, es económicamente factible, considerando una cuota de mercado del $17 \%$ que arroja una tasa interna de retorno de $36 \%$.

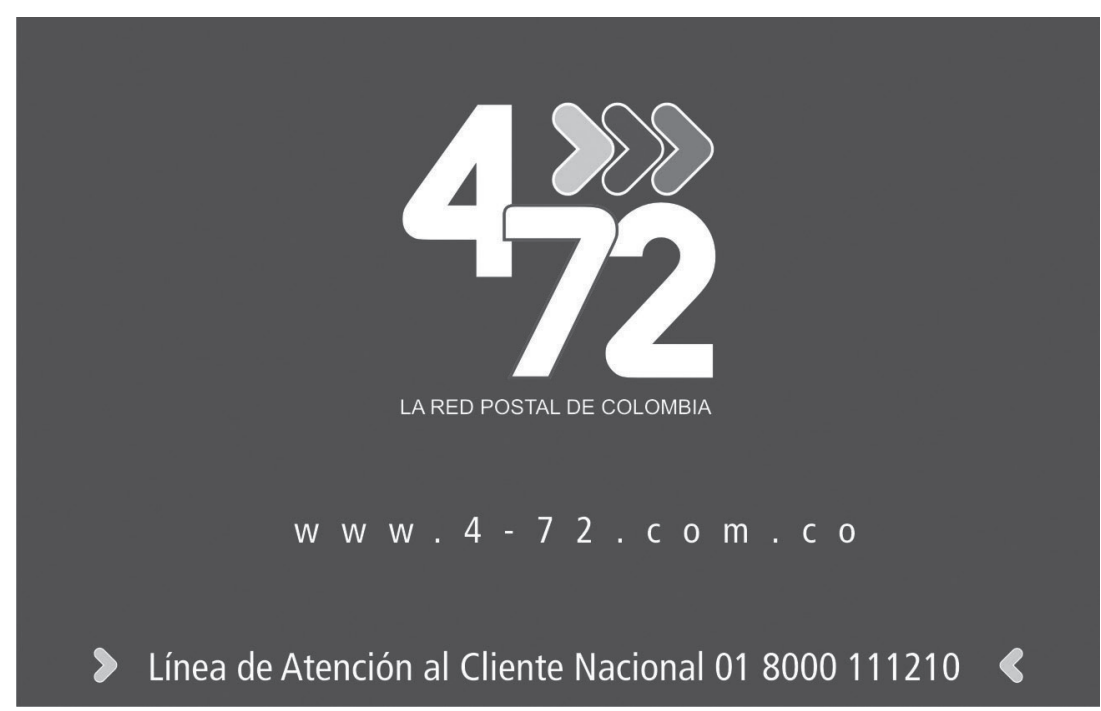




\section{REFERENCIAS BIBLIOGRÁFICAS}

Arango T., (2001). Edificios altos de mampostería en arcilla, Revista Terracota, Bogotá.

Asokan, P., Mohini, S., Shyam A., (2007). Solid wastes generation in India and their recycling potential in building materials. Build Environ 42: 2311-20.

Ayres, RU., (1997). Metals recycling: economic and environmental implications Resour Conserv Recycling, 21, pp. 145-173.

Berkhout, F., Smith, D., (1999). Products and the environment: an integrated approach to policy. Eur Environ, 9, pp. 174-185.

Boada Ortiz, A., (2003). El reciclaje, una herramienta, no un concepto. Reflexiones sobre la Sostenibilidad. Universidad Externado de Colombia. Centro de Gestión Ambiental. Bogotá.

Barra de Oliveira, M., (1999). Estudio de la durabilidad del hormigón deárido reciclado en su aplicación como hormigón armado. Trabajo de tesis de doctorado. Universidad Politécnica de Cataluña. Departamento de Ingeniería de la Construcción. España.

Buitrago, J.E., Salazar, M., (2013). Estudio de las Unidades Productoras de Materiales Cerámicos para la construcción, en la Asociación Industrial y Tecnológica de Arcillas Sugamuxi ONG. Centro de Investigación Observatorio, Universidad Pedagógica y Tecnológica de Colombia.

Cardona Gallo, M. M., (2007). Minimización de residuos: una política de gestión ambiental empresarial. Producción + limpia, vol I.

DANE (2013). Estadísticas de edificación, licencias de construcción. Recuperado de http://dane.gov.co/files/investigaciones/boletines/licencias/bol-lic-0ct13.pdf.

Ecocarbón (s.f.). Normas generales sobre muestreo y análisis de carbones. Gerencia de planificación de carbón, división análisis de reservas. Cuadernillo 1. Santafé de Bogotá; (s.e.).

Glinka, M. E., Vedoya, D. E., Pilar, C. A., (2006). Estrategias de reciclaje y reutilización de residuos sólidos de construcción y demolición. Jornadas de investigación. Secretaria de Investigación y Posgrado, Facultad de Arquitectura y Urbanismo Universidad Nacional del Nordeste, Argentina.

Gunduz. L., (2008). Use of quartet blends containing fly ash, scoria, perlitic pumice and cement to produce cellular hollow lightweight masonry blocks for non-load bearing walls. Construction and Building Materials 22, pp. 747-754.

Hart, SL. (1997). Beyond greening: strategies for a sustainable world. Harvard Bus Rev, 75 (1), pp. 66-76. 
Hernández, S., Fernández, C., Baptista, P., (2003). Metodología de la investigación. México: Mc Graw Hill.

Hincapié, A., Aguja, E., (2003). Agregado reciclado para morteros. Revista Universidad EAFIT. V. 39, (132), pp. 76-89. pp 45-50.

Lecitra, M., (2010). Reducir, reutilizar y reciclar: el problema de los residuos sólidos urbanos. GEIC, grupo de estudios internacionales contemporáneos. Derechos humanos y ambiente.

Leon, N. A. y otros (2008). Evaluación experimental de unidades sílico-calcáreas a partir de escoria de alto horno y cal hidráulica para mampostería. Revista de Ingeniería de Materiales, Universidad Nacional de Colombia.

Maldonado, A. (2006). Evaluación de la exposición a la contaminación en hornos de producción de ladrillo en Boyacá. Centro de investigaciones de Ingeniería Ambiental CIIA. Bogotá.

Mangesh V. M., Rahul V. R., Sachin A. M., (2013). Application of agro-waste for sustainable construction materials: A review. Construction and Building Materials, 38, 872-878.

Martinera, F., Seijo, P., Kennas, S., Machado, I., González, R. (2002). Waste to Energy Technologies Targeting the Poor. The Cuba Case Study. World Renewable Energy Congreso. Koeln, 29 June - 5 July.

Martinez, S., (1996). Reciclaje y tratamiento de residuos. Acta geológica hispánica. Vol 30, Número 1-3, pp 63-72.

Mclean, A., (2004). The science and technology of blast furnace slags. En: AISI. An intensive course: blast furnace ironmaking. Volume two. McMaster University. Hamilton, Ontario, Canada.

Meadows, D.H. (1992). Beyond the limits: global collapse or a sustainable future, London. (s.e.).

Medina, M., (1999). Reciclaje de desechos sólidos en América Latina. Frontera Norte, V 11, (21), Enero-Junio.

Raut, S.P., Ralegaonkar, R.V., Mandavgane, S.A., (2001). Development of sustainable construction material using industrial and agricultural solid waste: a review of waste-create bricks. Constr Build Mater; pp.25:4037-42.

Sarmiento, L., (2006). Contaminación en hornos de producción de ladrillo en Boyacá. Centro de Investigaciones en Ingeniería Ambiental CIIA. Universidad de los Andes. Bogotá.

Secretaria de Salud del Municipio de Sogamoso, informe 2012.

Umwelttechnik, B. \& Beratung, Gmbh, (2007). El Reciclaje reduce costes de manipulación en la Planta de elementos prefabricados. Tecnología del hormigón. PHI - Planta de Hormigón Internacional - 2.

Van der Vorst, M.R., (2003). Developing sustainable products and services. J Cleaner Prod, 11, pp. 883-895.

Walker S. A., (1999). Shattered visage lies sustainable design and local scale. International symposium on environmentally conscious design and inverse manufacturing. Ecodesign '99, Tokyo, Japan.

Weia, Yu-Ling, Chang-Yuan Lina, Shao-Hsiang Chenga, H. Paul Wangb, (2014). Recycling steel-manufacturing slag and harbor sediment into construction Journal of Hazardous Materials. Journal of Hazardous Materials 253-260 